\title{
Heart Drawing: A New Diagnostic Tool
}

\author{
Arthur Becker-Weidman ${ }^{1}$ \\ ${ }^{1}$ Center For Family Development, Attachment-Focused Treatment Institute, Williamsville, NY, USA \\ Correspondence: Arthur Becker-Weidman, Center For Family Development, 5820 Main Street, suite 406, \\ Williamsville, NY, 14221, USA. Tel: 1-716-810-0790. E-mail: AWeidman@Concentric.net
}

Received: March 3, 2016

Accepted: March 17, 2016

Online Published: March 31, 2016

doi:10.5539/res.v8n2p133

URL: http://dx.doi.org/10.5539/res.v8n2p133

\begin{abstract}
This paper presents a methodology for assessing a child's capacity to identify primary affective states, affect regulation, and affective experiences in a non-threatening manner. The methodology can be used with children from ages three years thru age nineteen years.

Background

A thorough assessment includes an evaluation of a person's capacity to identify and regulate emotions. Affect regulation requires the capacity to identify internal experiences of emotions. The Heart Drawing was developed as a non-threatening method for assessing a child's capacity to identify emotions. Most children enjoy drawing and the Heart Drawing is usually experienced by the child as non-threatening and enjoyable.

The Heart Drawing is a new, easy to use, and efficient tool that allows the clinician to assess a child's affect regulation functioning, affective range, and experience in a non-threatening manner. It can also be used to assess a child's insightfulness and capacity to identify internal affective experiences.
\end{abstract}

Method

The child is asked to select colors for the feelings expressive of mad, sad, glad, and scared from a group of nine primary colors. The child is then asked to draw a heart and to fill in the heart with the amount of each feeling that the child usually feels.

Results

Administration and discussion usually takes ten to fifteen minutes.

Conclusion

The article presents examples of drawings by children with various diagnoses and conditions along with a normative drawing for comparison. The methodology has been found to be very helpful in assessing a child's emotional status and capacity to regulate emotions.

Key Practitioner Message

1) Emotional regulation and the capacity to identify emotions is important for evaluation and treatment.

2) Projective drawing methods can be useful in assessing a person's ability to identify and regulate emotions.

3) The Heart Drawing is an efficient and effective method for assessing a person's capacity to identify and regulate emotions.

Keywords: attachment, trauma, dyadic developmental psychotherapy, affect regulation, assessment, projective test, art therapy, complex trauma

\section{Introduction}

The impetus for the development of this tool came from working with the House-Tree-Person (Buck, 1995) projective drawing test. That experience, the work with art therapists and the use of color, (Burkett et al., 2003) led to the development of this simple procedure to assess a child's emotional regulation capabilities and experience of feelings. The House-Tree-Person projective drawing test (HTP) demonstrated the projective utility and validity of using drawings to learn about a person's psychological and emotional states (Buck, 1995; Jolles, 1996; Wenck, 1997). Work with art therapists has demonstrated that drawings can be a powerful means of 
accessing a client's inner states and emotional experience (Bonny \& Kellogg, 1977; Gaitskil et al., 1982; Malchiadi, 1998; Oster, 2004).

The HTP demonstrated that comparing the color and pencil drawings reveal an individual's affect regulation capacity since color evokes emotion (Buck, 1995). A child's affective state can then be assessed by their relative use of different colors. In addition, there are certain feelings associated with certain colors (Oster, 2004; Rubin, 1999; Vass, 2012). Stereotypically, anger or mad is associated with red or black, blue with sad, yellow or orange with glad or happy, and gray or black with scared or frightened. The idea was to develop a method to assess a child's relative experience of emotions. Since feelings are often described as being located in one's heart, the procedure developed to have the child color in "their heart" with the relative amount of each feeling they experienced. In addition, it was hypothesized that if non-stereotypically colors were used, that would indicate that the child may know what the word means but have difficulty identifying the actual emotion. Difficulty identifying emotions is a causative dimension of affect regulation dysfunction and emotional dysregulation. The emotions, "mad, glad, sad, and scared" were selected because of their simplicity and that these emotions generally covered most of the primary emotional pallet.

This tool for assessment has been found to be very helpful in developing treatment plans for youth in the child welfare system who have presented with disorders of attachment and trauma (Becker-Weidman, 2010; Becker-Weidman, 2011), as well as with other children. The assessment tool has been useful in identifying which emotions a child has difficulty with and in identifying emotional regulation difficulties.

\section{Instrument Development}

This tool was developed over the last fifteen years while working with over 300 children who met the DSM-IV criteria for Reactive Attachment Disorder and the clinical criteria of Complex Trauma. This cohort was composed of an equal number of male and female children with a mean age was 10 years old (range, 3-18 years of age). A variety of living situations were represented, including children living with birth parents, adoptive parents, and foster parents, and those living in residential treatment centers, group homes, and children's homes. The majority of the children were from the United States and their ethnicities were broadly representative of the general population with approximately 50\% Caucasians, 20\% African-Americans, $15 \%$ Hispanics, and 15\% Asians. There were also 10-20 children from Canada, The Czech Republic, Finland, Singapore, and Slovakia. Finally, approximately $20 \%$ of the US group had been adopted internationally, primarily from Russia, China, Vietnam, Cambodia, Ethiopia, Liberia, and Columbia. The test was also administered to fifty children who had not experienced developmental trauma disorder nor had disorders of attachment to evaluate normative responses.

\section{Procedure}

1) Sit across the table from the child.

2) Place a sheet of unlined white paper in front of the child.

3) Place nine crayons at the top of the page. The color of the crayons should be red, blue, orange, yellow, gray, black, green, brown, and purple.

4) Ask the child, "What color would you pick for mad?" After the child selects a color, point to the bottom left corner of the paper and ask the child to write "mad" on the paper. Then have the child place that color next to the paper.

a) If the child does not know how to spell a word or asks for the spelling, provide the correct spelling. However, if the child attempts to write the word and does not spell it correctly, do not correct the child.

5) Ask the child, "What color would you pick for sad?" After the child selects the color, say, "write sad next to mad." Wait to see if the child places the crayon next to the one for mad. Most children will and a failure to do so may indicate difficulty with the executive function of sequencing and/or working memory. If the child does not place the crayon next to the one selected for mad, have the child do so.

6) Ask the child, "What color would you pick for glad?" After the child selects a color, most children will now understand the sequence and write the word glad next to sad and place that crayon next to the other two. If not, instruct the child to do so.

7) Ask the child, "What color would you pick for scared?" After the child selects a color, most children will now understand the sequence and write the word scared next to glad and place that crayon next to the other three. If not, instruct the child to do so.

8) With your finger trace a large heart in the middle of the page while you say, "Please draw a large heart here 
in the middle of the page and use any color you want."

9) After the outline of the heart has been drawn instruct the child as follows: "If that is your heart, the part of you that feels feelings, color in the heart with the amount of each feeling that you usually have. If you have a lot of one feeling, put a lot of that color in, if you only have a little of a feeling, color in a little bit. Color in the whole heart."

a) With older children you can instead ask them to, "Color in the heart with the proportion of each feeling that you usually have most of the time."

b) With younger children or those who may have cognitive impairment you should ask "which feeling is that one?" each time as they pick up a crayon.

10) After the heart is colored in you can use it to segue into a discussion of feelings. You may begin by asking, "which feeling do you have the most of?" and follow up with, "what makes you feel [dominant emotion]," "what do you do when you are [dominant emotion]?" and other relevant questions. Continue by asking, "which is the second largest feeling?" and continue until you have explored each of the feelings.

\section{Drawing Interpretation}

Although this tool is primarily used to facilitate discussion, evaluation of the drawing is also important. The drawing should be evaluated for appropriate color choice and normal proportion of each color within the heart. In addition, each color should be in its own area. When a child had one or more emotions in several separate sections that often indicates that the child has difficulty with the executive functions of planning and use of materials. Leaving out a color is significant and often means that the child has some difficulty with that feeling. A normal color choice for the emotion mad is red or black, for sad is blue, for glad is yellow or orange, and for scared is gray or black. Non-normative color choices usually reflects that the child can define what the word means, but either cannot identify the emotional experience or had some difficulty with that emotion. Although there is some variation in the normal proportion of each color within the heart the emotion glad is dominant in normative children; typically greater than $60 \%$. Traumatized children and those with disorders of attachment typically make unusual color choices and have color proportion indicative of emotional dysregulation. Typically, the feeling "glad" will occupy less than half the heart, while one or more of the other feelings will occupy one quarter or more of the heart. When the heart is colored in a disorganized or fragmented manner that can reflect executive function impairments. Figure 1 demonstrates a normal drawing with appropriate color choices and proportion of each color within the heart.

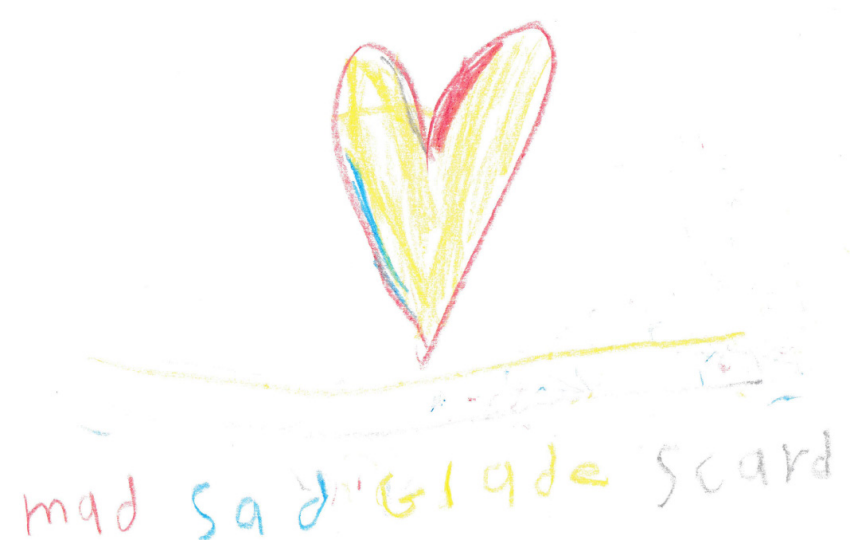

Figure 1. Eight-year old drawing by typical or "normal" child

\subsection{Normal Drawing}

In Figure 1 is a drawing by an eight year old girl who was a neighbor of a therapist in training at the Center for Family Development. The child had good grades in school, was involved in several extra-curricular activities, and had a group of friends with whom she interacted with regularly, one older brother and a younger sister, and supportive attentive parents. Note that "glad" is the dominant emotion and occupies approximately $90 \%$ of the heart and appropriate color choices were made with red for mad, blue for sad, yellow for glad, and black for scared. The use of the color red for the heart outline is the most common color selected. 


\section{*}

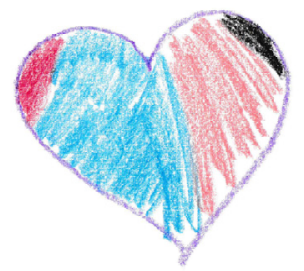

\section{Mad Sad Glad Scared}

Figure 2. Fifteen-year old child involved in custody dispute: Feeling Sad

\subsection{5-Year Old Girl; Custody Dispute between Parents}

In Figure 2 one atypical color is used for the feeling, "Glad," and a high proportion of the feeling, "Sad" is in the drawing. This fifteen year old girl felt conflicted and torn between her mother and father who were engaged in a bitter custody battle over this child and her ten year old brother. The girl was brought to treatment because of depression, falling grades, anger outbursts, and defiance.
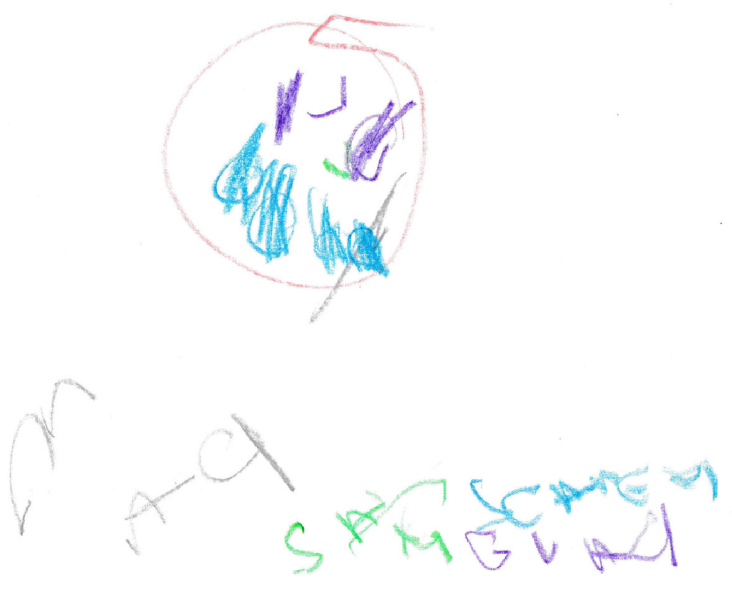

Figure 3. Five year old victim of neglect: ARND \& Neglect

\subsection{Five-Year Old Boy: ARND and Neglect}

Drawn by a five year old boy removed from his birth family at one year of age because of neglect. Prenatal exposure to alcohol resulted in significant executive function dysfunction as measured by the Behavior Rating Inventory of Executive Function. The child met clinical criteria for Alcohol Related Neurodevelopmental Disorder (ARND). Unusual colors used for sad, glad, and scared. In addition, the chaotic and incomplete filling in of the heart is a function of ARND and the executive function impairments in use of materials and planning. 


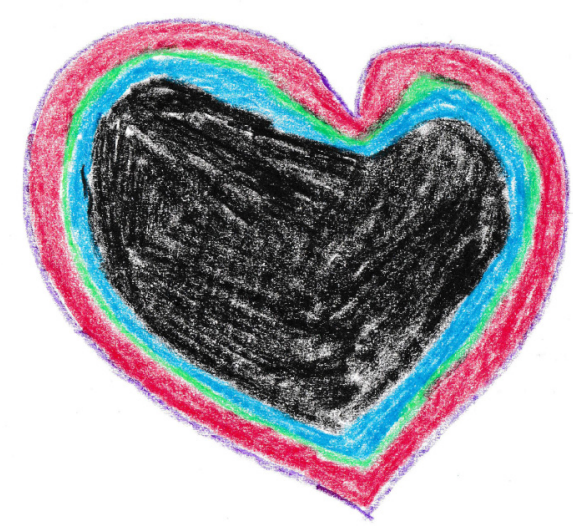

\section{mad Sad Glad Scared}

Figure 4. Sixteen-year old in residential treatment: Complex Trauma \& Reactive Attachment Disorder

\subsection{Sixteen-Year Old Boy: In Residential Treatment}

Drawn by a sixteen-year old boy in residential treatment. Prior to adoption at age nine, he had been in eight different foster homes. He was removed from his birth family at age three years because of physical abuse and neglect. Placed in residential treatment because of violent rages. The child met clinical criteria for Complex Trauma and DSM-IV diagnosis of Reactive Attachment Disorder.
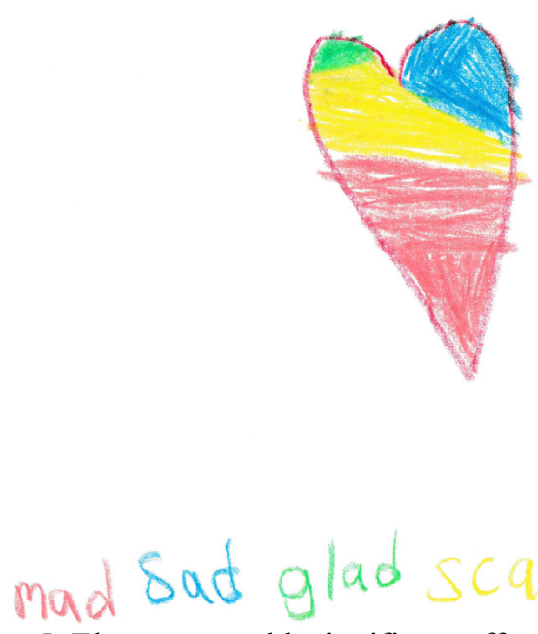

Figure 5. Eleven-year old: significant affect dysregulation

\subsection{Eleven-Year Old Boy: Adopted at Age Seven Years}

Drawn by an eleven-year old boy, adopted at age seven years. He was removed from his birth family at the age of four years old because of neglect. In this drawing unusual colors for glad and scared are used. In addition, the proportion of colors/feelings indicates little happiness. This child was brought to treatment because of frequent temper tantrums and rages at home and at school, where he was placed in a 6:1:1 class for children with emotional and behavioral disorders.

\subsection{Validation of Analysis}

A qualitative analysis of Heart Drawings prepared during the initial meeting with children compared with later experience in therapy and with a review of the children's histories provided validation for several of the assumptions regarding the instrument.

First, it became apparent that children who used stereotypical colors tended to have notably more demonstrated age-appropriate affect regulation capabilities than children who selected atypical colors. These impressions 
became apparent as therapy progressed and in a review of the child's history and presenting problems. In addition, in some instances the Heart Drawing was administered at the end of treatment and in all instances it was found that children who had selected atypical color(s) during assessment, used typical colors for the emotions at the end of treatment.

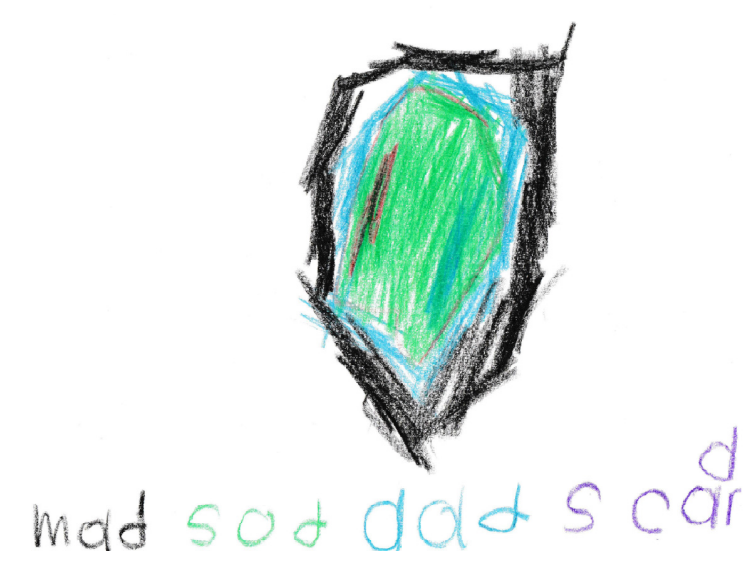

Figure 6. Six-year old: victim of physical and sexual abuse

\subsection{Atypical Use of Colors}

Drawn by a six-year old girl who had been in four foster placements before the current placement. She was removed from her birth family at four and half years of age as the result of physical and sexual abuse. She met the clinical criteria for Complex Trauma and has a DSM-IV diagnosis of Reactive Attachment Disorder. In her drawing we see several atypical colors for feelings.

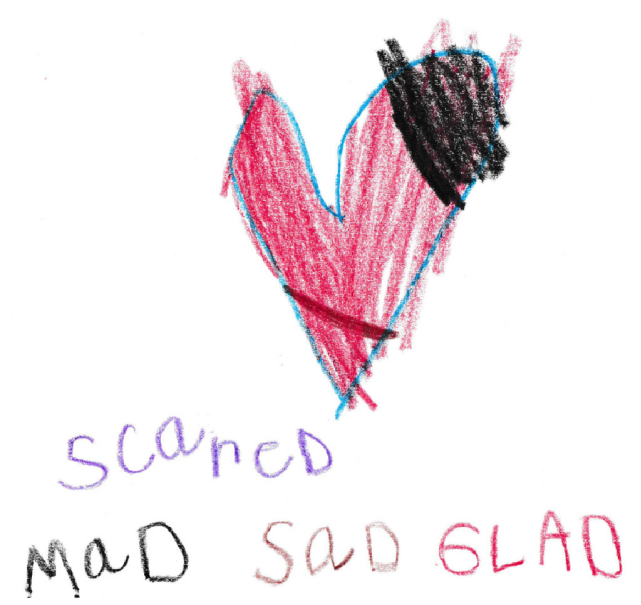

Figure 7. Seven-year old: Reactive Attachment Disorder

\subsection{Atypical Use of Colors}

Drawn by a seven-year old girl with a DSM-IV diagnosis of Reactive Attachment Disorder. This child was has a significant history of neglect and abuse. She was living with her birth family at the time of the assessment. In this drawing unusual colors for sad, glad, and scared are exhibited.

Second, it was frequently observed that when a child only had one atypical emotion-color or left out one feeling, that emotion as particularly problematic for the child. So, for example, one child left out the feeling sad from his Heart Drawing. This was an emotion he found most difficult to tolerate and would often become dysregulated if sad experiences were discussed and evoked in treatment or at home. It should also be noted that on occasion a 
child will completely fill in the heart with the color selected for glad. In those instances it was found that the child was notably guarded and avoidant.

\section{Sad left out}

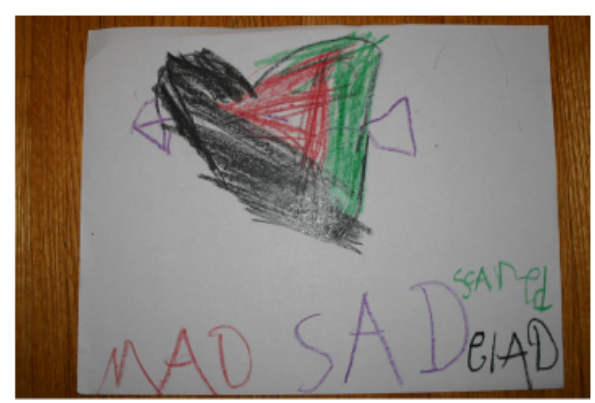

Figure 8. Nine-year old: Bipolar disorder

\subsection{Sad Left Out of Drawing}

In Figure 8 the emotion "sad" has been left out. This nine year old boy had a diagnosis of Bipolar Disorder I and was living with his birth family. He was brought into treatment because of frequent emotional "melt-downs," rages, and temper tantrums. Any discussion of sad feelings led quickly to the child becoming dysregulated and violent.

Third, it was found that the manner in which the child completed the drawing could reveal information about their executive function of planning and use of materials. Most children fill the heart in an orderly manner, one color at a time. When the child fills in the heart in a disorganized manner, having multiple sections of each color that is a substantial indication of some cognitive impairment of the executive functions of planning and of use of materials.

\section{Disorganized Heart}

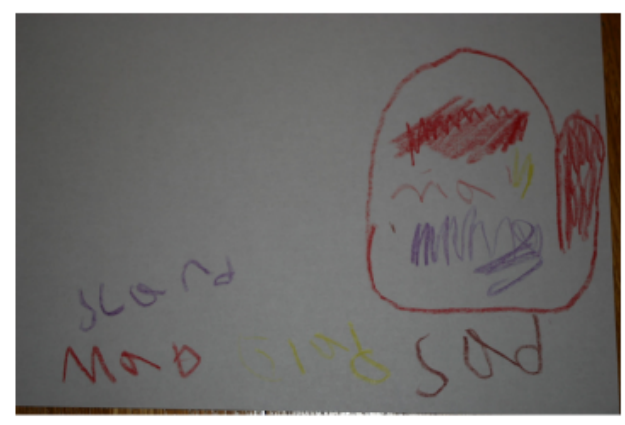

Figure 9. Ten-year old: prenatal exposure to methamphetamine and alcohol

\subsection{Disorganized Drawing Indicative of Arnd}

Figure 9 is of a ten-year old girl who selected unusual colors for sad and scared. In addition, in response to the request to "draw a large heart and color it in with the amount of each feeling you usually feel most of the time. If you have a lot of one feeling, put a lot of that color in and if you only have a little bit of a feeling color in a little bit of that color. And color in the whole heart." She initially began writing "mad" with red and when redirected, she colored in the heart in this partial manner. The child had been prenatally exposed to alcohol and was born positive to methamphetamine.

Fourth, the proportions of each emotion-color used reflect the child's actual experience, except as noted above in 
those instances where a child completely fills in the heart with glad. As seen in the above figures, most often we find that glad comprises less than $50 \%$ of the heart with the most problematic affect taking up the first or second largest portion of the Heart Drawing.

Fifth, we observe significant changes in the proportions of emotion-color from the assessment to the end of treatment. Typically, the feeling glad fills up $2 / 3^{\text {rds }}$ to $4 / 3^{\text {ths }}$ of the drawing, with the other emotions filling in the balance.
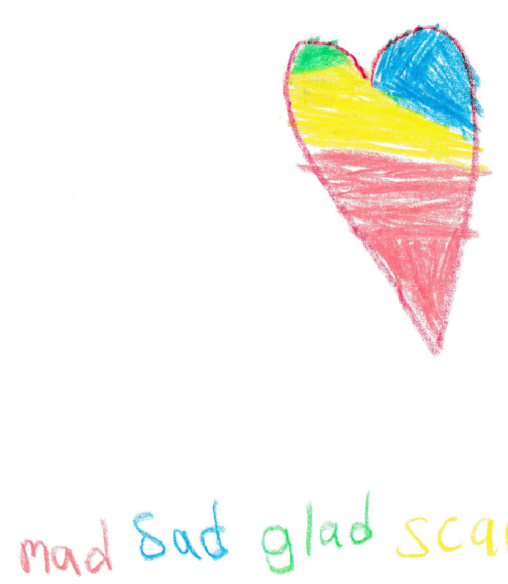

Figure 10. Pre-treatment drawing: six-year old: victim of physical and sexual abuse

\subsection{Pre Treatment 11-Year Old Boy}

See Figure 6 Above for details.

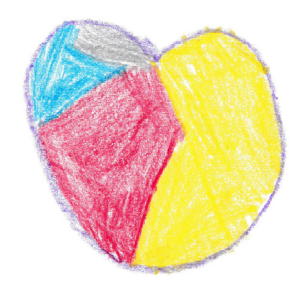

\section{Ma.d Sad}

Figure 11. Post treatment drawing of six-year old treated with dyadic developmental psychotherapy

\subsection{Post-Treatment}

After six months of treatment using Dyadic Developmental Psychotherapy, an attachment-focused treatment provided by a therapist certified in Dyadic Developmental Psychotherapy by the Attachment-Focused Treatment Institute, we see several significant changes in his drawing. The colors selected are the more typical colors. In addition, the proportions of the feelings have changed with mad, and scared decreasing, glad increasing, and sad staying approximately the same size.

\section{Conclusions}

The "Heart Drawing" is a time-economical, novel tool that can be used to assess affect regulation functioning, affective range, and experience in patients with Reactive Attachment Disorder, Post-Traumatic Stress Disorder, and the clinical formulation of Developmental Trauma Disorder. This procedure can be used to monitor treatment response and document improvement in the child's capacity to identify and regulate emotions. 
The normative colors are $\mathrm{mad}=$ red or black, sad=blue, glad=yellow or orange, and scared=gray or black. The use of non-normative colors usually reflects that the child can define what the word means, but either cannot identify the emotional experience or had some difficulty with that emotion. Traumatized children and those with disorders of attachment such as Reactive Attachment Disorder, or who meet the clinical formulation of Developmental Trauma Disorder, typically select unusual colors for the feelings and have proportions of feelings indicative of emotional dysregulation and related difficulties. Typically, the feeling glad will occupy less than half the heart, while one or more of the other feelings will occupy one quarter to a third or more of the heart. When the heart is colored in a disorganized or fragmented manner that can reflect executive function impairments.

This is a preliminary description of what may best be described at this time as a communication-facilitation tool. The paper describes qualitative interpretations of colors and emotions. Research validating these interpretations would be a significant improvement and support the use of the Heart Drawing as a more rigorous diagnostic tool. Currently the Heart Drawing is a projective and qualitative methodology that would benefit from research that would allow for quantative analysis and validation of the qualitative hypotheses described in this article.

The Heart drawing is a time-economical assessment tool that provides a non-threatening access to the child's affective states. The entire procedure can usually be completed in ten minutes. The procedure can be used to assess progress in the treatment of trauma and related disorders that cause affective difficulties.

\section{Acknowledgements}

No Funding was received as part of this work.

\section{References}

Becker-Weidman, A. (2010). Dyadic Developmental Psychotherapy: Essential Practices \& Methods. Lanham, MD: Jason Aronson.

Becker-Weidman, A. (2011). The Dyadic Developmental Psychotherapy Casebook. Lanham, MD: Jason Aronson.

Bonny, H., \& Kellogg, J. (1977). Mandalas as a Measure of Change in Psychotherapy. American Journal of Art Therapy, 16, 126-130.

Buck, J. (1995). House-Tree-Person Projective Drawing Technique Manual and Interpretive Guide. Los Angles: Western Psychological Services.

Burkitt, E. et al. (2003). Children's Colour Choices for Completing Drawings of Affectively Characterised Topics. Journal of Child Psychology and Psychiatry, 445. http://dx.doi.org/10.1111/1469-7610.00134

Gaitskill, C. et al. (1982). Children and Their Art. New York: Harcourt Brace Jovanovich.

Golomb, C. (1992). The Child's Creation of a Pictorial World. Berkeley and Los Angeles: University of California Press.

Jolles, I. (1996). A Catalog for the Qualitative Interpretation of the House-Tree-Person (HTP). Los Angles: Western Psychological Services.

Levick, M. (1998). See What I'm Saying: What Children Tell Us Through Their Art. Regal Printing ltd., Hong Kong.

Malchiodi, C. (1998). Understanding Children's Drawings. New York: Guilford Press.

Oster, G. (2004). Using Drawings in Assessment and Therapy: A Guide for Mental Health Professionals. New York: Brunner/Mazel.

Rubin, J. (1999). Art Therapy. New York: Brunner/Mazel.

Vass, Z. (2012). A Psychological Interpretation of Drawings and Paintings. The SSCA Method: A Systems Analysis Approach. Alexandra Publishing.

Wenck, L., \& Stanley. (1997). House-Tree-Person Drawings: An Illustrated Diagnostic Handbook. Los Angles: Western Psychological Services.

\section{Copyrights}

Copyright for this article is retained by the author(s), with first publication rights granted to the journal.

This is an open-access article distributed under the terms and conditions of the Creative Commons Attribution license (http://creativecommons.org/licenses/by/3.0/). 